\title{
Universidad y currículo: El caso de la Universidad del Tolima (1955 a 1962) ${ }^{1}$
}

\author{
University and Curriculum: The case of Universidad del Tolima (1955- \\ 1962) \\ Universidade e currículo: o caso da Universidade de Tolima (1955-1962)
}

Recepción: 15/08/2019

Evaluación: 12/12/2019

Aceptación: 01/04/2020

Artículo de Investigación - Revisión

https://doi.org/10.19053/01227238.10904

Sonia Giraldo Pérez ${ }^{2}$

https://orcid.org/0000-0002-0018-3199

Universidad del Tolima (Colombia)

\begin{abstract}
RESUMEN
Objetivo: Con esta comunicación configuraron tres de las facultades del área se busca presentar un análisis de la estructura curricular que se materializó en los primeros programas académicos en la Universidad del Tolima entre 1955 y 1962. Expone, para ello, algunos motivos políticos que conllevaron a acogerlos en la naciente universidad. Metodología: La investigación responde a un enfoque histórico-hermenéutico, con un diseño orientado hacia el análisis documental. Estrategias: Las fuentes principales están constituidas por los actos administrativos emanados por el Consejo Directivo de la Universidad del Tolima y su análisis mediante la descripción de los mismos. Originalidad: Presentamos, en consecuencia, algunos programas ofertados por la Universidad del Tolima que agropecuaria y dos institutos tecnológicos, agrupados, todos, en siete escuelas. Conclusiones: El estudio sugiere que las vicisitudes acaecidas en este periodo llevaron al Estado a redireccionar las políticas educativas mediante la invitación de misiones académicas internacionales que contribuyeron a crear instituciones educativas que, a su vez, permitieron la creación de universidades en algunas regiones de Colombia. Como caso particular del análisis, la Universidad del Tolima se destaca ya que, desde su creación, buscó la formación de profesionales para el sector agropecuario y tecnológico.

Palabras clave: Estructura curricular; plan de estudio; Universidad del Tolima.

1 Este artículo hace parte de los desarrollos académicos de la línea de investigación "Pedagogía, Currículo y Conocimiento", coordinada por el Dr. Carlos Jilmar Díaz Soler desde la Universidad Distrital Francisco José de Caldas.

2 Estudiante del Doctorado en Ciencias de la Educación -RUDECOLOMBIA-CADE-Universidad del Tolima. Profesional de la Oficina de Autoevaluación y Acreditación de la Universidad del Tolima, correo electrónico: sgiraldop@ut.edu.co.
\end{abstract}




\section{ABSTRACT}

This article aims at presenting an analysis of the curricular structure that came to the first academic programs at the Universidad del Tolima, between 1955 and 1962. It introduces the arguments which bearing in mind political reasons will led them in the birth of the university, once analyzed from a documentary corpus organized around educational legislation and which, at that time, it contributed to guiding the functioning of institutions of professional education. Consequently, we present some programs offered by Universidad del Tolima that configured three of the Faculties of the agricultural field and two technological institutes, all grouped in seven schools. The study suggests that the vicissitudes that happened in this period led the state to redirect educational policies through the invitation of the international Academic Missions that contributed to create educational institutions and so, to allow the creation of universities in some regions of Colombia. The Tolima university, as particular case, of the analysis, since its origins, it has sought the development of professionals for the agricultural and technological field.

Keywords: Curricular structure; study plan; Tolima university.

\section{RESUMO}

Com esta comunicação se busca apresentar uma análise da estrutura curricular que se materializou nos primeiros programas acadêmicos na Universidade de Tolima, entre 1955 e 1962. Expõe, para isso, argumentos tendentes a explicar algumas razões políticas que levaram a aceita-los na nascente universidade, examinados a partir de um corpo documental organizado em torno da legislação educativa e que, a seu tempo, contribuiu para orientar o funcionamento das instituições de educação superior. Apresentamos, em consequência, alguns programas ofertados pela Universidade de Tolima que configuraram três das Faculdades da área agropecuária e dos institutos tecnológicos, agrupados, todos, em sete escolas. $O$ estudo sugere que as vicissitudes ocorridas nesse período levaram o Estado a redirecionar as políticas educacionais mediante o convite de Missões Acadêmicas internacionais que contribuíram para criar instituições educacionais que, por sua vez, permitiram a criação de universidades em algumas regiões da Colômbia. A universidade de Tolima, como um caso específico da análise, se destaca, uma vez que, desde sua criação, buscou a formação de profissionais para o setor agropecuário e tecnológico.

Palavras-chave: Estrutura curricular; plano de estudo; Universidade de Tolima. .

\section{INTRODUCCIÓN}

El llevar a cabo un análisis sobre la estructura curricular de la Universidad del Tolima en el periodo comprendido entre 1955 y 1962 es destacable debido a su relación con los acontecimientos políticos vividos en el país luego de los sucesos en torno a lo que se denominó el "Bogotazo"3.

3 Nombre que se le dio al momento histórico ocurrido en Colombia el 9 de abril de 1948, luego del asesinato, en la ciudad de Bogotá, del caudillo liberal y candidato presidencial Jorge Eliécer Gaitán. Analistas políticos, sociales e históricos, destacan que este acontecimiento contribuyó a generar una "ruptura radical del orden político, cultural y social en el marco del capitalismo histórico en plena fase de industrialización y urbanización”. Autores colombianos como Jefferson Jaramillo Marín, en su texto Pasados y presentes de 
En ese momento se establece una fuerte crítica sobre la educación en general y específicamente sobre la universidad, acerca de su sentido y su función en el desarrollo del país. Fruto de este debate es la contratación, por parte del Estado colombiano, de misiones académicas internacionales y sus consecuentes recomendaciones, que elaboran en torno a la educación vista globalmente y, en particular, sobre el horizonte esperado para las instituciones de educación superior.

A partir de un análisis documental que centra su atención en las disposiciones materializadas en la política estatal para las universidades y de las disposiciones reglamentarias que desde el Ministerio de Educación Nacional se emitieron para las universidades, se pretende analizar los actos administrativos presentados por los consejos Superior y Directivo de la Universidad del Tolima entre 1955 y 1962. Guían este escrito preguntas en torno a cómo se dio el proceso de institucionalización en la Universidad del Tolima, cómo se asumió la formación superior en el marco de la implementación de sus currículos, qué estructuras curriculares se materializaron.

La Universidad del Tolima inició actividades académicas en 1955, con la puesta en marcha de la Facultad de Ingeniería Agronómica. En 1956 pone en funcionamiento la Escuela de Bellas Artes, anexando, además, cuatro escuelas: Pintura, Escultura, Cerámica y Decorado y Dibujo. En 1961 se gesta el Instituto Politécnico con tres escuelas: Topografía, Auxiliares de Enfermería y Técnicos Electricistas, así como la creación de dos facultades de corte agropecuario: Medicina Veterinaria y Zootecnia e Ingeniería Forestal.

\section{Las estructuras curriculares: esbozos para pensar su transformación}

Con el término universitas se denominó al conjunto de personas reunidas alrededor del conocimiento: unos en torno al saber organizado y su enseñanza; otros, los estudiantes, por su lado, se denominaron universitas scholarum ${ }^{4}$. Población académica organizada en corporaciones, las universitas ${ }^{5}$, que pautan su organización y funcionamiento sobre la base de un estatuto general independiente que, con el surgimiento de las universidades a principios del siglo XII en Europa, contribuye a darle un nuevo aire a la organización y difusión del conocimiento.

La estructura curricular de la Universidad de Bolonia (1088), por ejemplo, se organizó en tres escuelas con diferentes escenarios: la Municipal, para los estudios jurídicos; la Monástica, donde se impartían las claves del derecho canónico y la Catedralicia, para los estudios de artes. Por su parte, en Oxford (1187), los estudios se centraron en las artes, la medicina y la teología. La Universidad

la violencia en Colombia. Estudios sobre las comisiones de investigación (1958/2011) (Bogotá: Editorial Pontificia Universidad Javeriana, 2014) y Gonzalo Sánchez con su obra Los días de la revolución: gaitanismo y 9 de abril en provincia (Bogotá: Centro Cultural Jorge Eliécer Gaitán, 1984), retratan el momento social vivido en el país durante el Bogotazo.

4 Alfonso Borrero Cabal, La universidad. Estudios sobre sus orígenes, dinámicas y tendencias (Bogotá: Editorial Pontificia Universidad Javeriana, 2008), 37.

$5 \quad$ Ibíd., 36. 
de París (1208), a su vez, contó con cuatro facultades, tres de ellas de estudios superiores para el Derecho Canónico, Medicina y Teología y, la cuarta, llamada inferior, para los estudios de artes; además, los grados que se impartían eran: bachiller, maestro y licenciado ${ }^{6}$. Ahora bien, tanto la Universidad de París como la de Bolonia otorgaban la ius ubique docendi, es decir, una licencia concedida por el papa o el emperador a quienes iban a enseñar7.

La estructura curricular materializada en este periodo histórico, que buscaba darle una organización a la institución universitaria, tomó para ello a las artes liberales y las dividió en dos: el trivium y el quadrivium ${ }^{8}$. El trivium formaba parte de las artes liberales de las tres ramas de la oratoria: la gramática, la dialéctica y la retórica; el quadrivium, por su parte, se conformó con las artes matemáticas: aritmética, geometría, astronomía y música; de esta manera se unió lo que muchos pensadores en filosofía desearon en su momento, el pensamiento filosófico y el matemático, como forma fundamental de reflexión ${ }^{9}$.

En territorio americano este movimiento de ideas se materializó en la creación de diferentes escuelas: evangelizadoras, escuelas primarias y colegios de secundaria, destinadas a distintos grupos sociales, con lo cual también se abren las puertas a la fundación de universidades, replicando, a su vez, la estructura curricular, los planes de estudio y los reglamentos de las universidades de Salamanca y Alcalá de Henares ${ }^{10}$.

Hacia 1510, en Santo Domingo, la Orden de los Predicadores -dominicos - , crea los Studium generale para la formación de los novicios, erigida como la primera universidad pontificia y bajo la tutoría de la Universidad de Salamanca, mediante la bula In Apostolatus Culmine (1538). La fundación de la Universidad San Marcos de Lima, en 1551, inicia actividades con cátedras de teología y filosofía. En 1553, bajo la figura de Cédula Real, se funda la Universidad de México.

Las directrices académicas de las universidades de Salamanca (1244) y Alcalá de Henares (1499), privilegian el establecimiento en Hispanoamérica de estructuras curriculares centradas en las ciencias, las matemáticas y la medicina $^{11}$, lo cual es un indicio de la circulación, el establecimiento y transmisión de los saberes en las instituciones, incluso con el cambio de contenidos en los currículos, en donde nuevos saberes son puestos a disposición mediante la transformación de las universidades.

\footnotetext{
6 María Clara Ibarra Losada, "Fundación de la universidad pública del Huila: años del Itusco" (tesis de maestría en Historia, Universidad Nacional de Colombia, 2011), 29. 30.

7 Borrero Cabal, La Universidad, 38.

8 El saber tenía, en el periodo medieval, dos caminos: las artes mecánicas y las artes liberales. Las primeras hacían referencia a los oficios que demandaban fuerza física: lanificium, armaturam, navigationem, agriculturam, ventationem, medicinam, theatricam, llamados oficios serviles, propios de siervos o esclavos. La segunda vía, las artes liberales, eran el escalón más alto de la educación, destinada a quienes podían acceder al conocimiento a través del ejercicio del intelecto. De esta manera, las artes liberales daban cuenta del "hombre libre" a través de las disciplinas académicas.

9 Borrero Cabal, La Universidad, 50.

10 Ibíd., 442-443.

11 Ibíd., 449.
} 
Para el caso de Brasil, por ejemplo, la instalación de las primeras ecole de corte napoleónico ${ }^{12}$ fue producto de las recomendaciones de diferentes misiones de científicos y artistas franceses que contribuyeron a impulsar las artes, la arquitectura, la pintura y la música. La Universidad de San Felipe de Chile es otro caso emblemático, en donde Andrés Bello ${ }^{13}$ (1781-1865) planteó cambios trascendentales a la educación que se constituyeron en modelo para el resto de las universidades de Latinoamérica. Modelo universitario que ahora era asumido como un órgano educativo de la nación, entregando a la universidad la supervisión de toda la labor educativa; encargada de definir la estructura curricular, diseñaría los planes y programas de estudio, escogería los textos y planearía los métodos de enseñanza, además, de abrir el horizonte académico hacia el conocimiento humanístico, científico y literario de su contexto. En palabras de José Joaquín Bruner:

\begin{abstract}
Debia estudiar su historia y preparar sus futuros adelantamientos materiales y morales; debía conocer su geología, su flora, su fauna, todos sus accidentes físicos; debía cooperar al desenvolvimiento de su industria y de su comercio; debía observar las enfermedades propias de nuestro clima, y sus preservativos; debía atender a la utilidad práctica, a los resultados positivos, a las mejoras sociales. ${ }^{14}$
\end{abstract}

En este brevísimo recuento vale la pena mencionar que parte de la transformación de las instituciones se llevó a cabo gracias al ímpetu del movimiento de Córdoba, Argentina (1918), donde un grupo de estudiantes exigió "planes de estudio modernos, contacto con la ciencia, docentes con autoridad basada en su saber, un clima cultural abierto a las novedades del país y de la época"15.

\title{
2. Universidad y currículo: el caso colombiano
}

En Colombia encontramos los inicios de la universidad de la mano de la Iglesia y el gobierno central de la Nueva Granada ${ }^{16}$. Surgen allí las primeras universidades: Santo Tomás, en 1586, de la orden de los dominicos; la Javeriana, en 1622, organizada por los jesuitas; San Nicolás de Mira, en 1694, fundada por

12 El modelo napoleónico tuvo su origen en Francia en el periodo moderno. Es un modelo fuertemente influenciado por la unión entre la Iglesia católica y el Estado, que se refleja en la forma como se establecen los estatutos académicos, los controles, los estándares de calidad, los requisitos para la obtención del título y con una gran sumisión al Estado y total indiferencia hacia la investigación. Este modelo se aplicó en España, Francia y Argentina, entre otros.

13 Andrés Bello nació en Caracas, Venezuela, el 29 de noviembre de 1781. Fue humanista, político, jurista y uno de los intelectuales más influyentes del siglo XIX. Además de su aporte a la educación y la cultura, jugó un destacado rol en la planeación de la institucionalidad que dio forma a Chile como nueva nación. Resalta su aporte a la educación y la cultura, así como el impulso que su influencia le dio al movimiento literario de 1842. Fue profesor en el Instituto Nacional, redactor de El Araucano y se desempeñó como rector de la naciente Universidad de Chile desde 1843 hasta su muerte, en 1865.

14 José Joaquín Brunner, Educación Superior en América Latina: cambios y desafios (Chile: Fondo de Cultura Económica, 1990$), 25$.

15 Ibíd., 32.

16 Durante la Colonia, por orden del rey Carlos V se crea en Colombia un orden político denominado Real Audiencia de la Nueva Granada. La Real Audiencia se instala en abril de 1550 y estaba conformada por cinco oidores y un presidente. Los fallos eran apelables únicamente en España, ante el Consejo de Indias. 
los agustinos; San Pedro Apóstol, en $1806^{17}$. La estructura curricular de estas instituciones conservan el trivium y cuadrivium como horizonte y el método de enseñanza fue escolástico, caracterizado por la dictatio y la disputatio. Para el caso de la Universidad Javeriana, en 1623, su organización académica se dio a través de los Ratio Studiorum ${ }^{18}$.

Estas instituciones, que privilegiaban la enseñanza del latín como idioma, se dedicaban a la instrucción por ocho años, en Artes, Teología y los Cánones ${ }^{19}$. Se iniciaba con los estudios superiores, que tomaban tres años y otorgaban el grado de bachiller en Artes o Filosofía, con un currículo integrado por Gramática, Retórica, Lógica, Metafísica, Matemáticas y Física. Luego se accedía a los estudios de bachiller en cánones y leyes, con tres cursos dedicados a estudiar los decretos, epístolas y cánones o normas conciliares para terminar con el grado de doctor. Los exámenes, denominados "La tremenda", giraban en torno a un texto seleccionado al azar y eran de tipo oral con pregunta y contrapregunta ${ }^{20}$.

En el marco de sus particularidades históricas, la Universidad Republicana (1826-1842) se erigió durante las presidencias de los generales Santander y Bolívar. El decreto del 18 de marzo de 1826 dio origen a las universidades centrales del Estado colombiano en Caracas, Bogotá y Quito. Su estructura curricular y planes de estudio permitieron crear las facultades de Filosofía, Teología, Jurisprudencia, Medicina y Ciencias Naturales en el marco de una estructura política centralista y de control del Estado ${ }^{21}$. Característica de este nuevo momento para la institución y su currículo fue el ingreso de las Ciencias Naturales, abriendo el horizonte de pensamiento a la enseñanza de los saberes modernos. Así, por ejemplo las asignaturas obligatorias para las clases de Filosofía y Ciencias Naturales serían, en adelante, "matemáticas, filosofía, geografía y cronología, lógica, ideología y metafísica, moral y derecho natural, historia natural en sus tres reinos, química, física experimental, astronomía y mecánica analítica y celeste, botánica y agricultura, zoología y mineralogía, arte de minas y geognosis" 22 .

Con el decreto del 8 de noviembre de 1825 se ordenó enseñar la legislación de Jeremías Bentham ${ }^{23}$ (1748-1832), institucionalizando la enseñanza de dos tratados: el de Legislación y el de Economía, asunto que no pasó desapercibido.

17 Diana E. Soto Arango, "Aproximación histórica de la universidad colombiana", Revista Historia de la Educación Latinoamericana vol. 7 (2005).

18 Borrero Cabal, La Universidad, 449.

19 Ibarra Losada, "Fundación de la universidad", 39.

20 Ibíd.

21 Soto Arango, “Aproximación histórica”, 12.

22 Jorge Arias de Greiff y Clara Helena Sánchez, “Antecedentes de la Facultad de Ciencias”, en Facultad de Ciencias: fundación y consolidación de comunidades científicas, ed. Germán Cubillos (Bogotá: Unibiblos Universidad Nacional de Colombia, 2006), 15-58.

23 Jeremías Bentham, pensador inglés llamado el padre del utilitarismo. Su obra magna Introducción a los principios de la moral y la legislación (1789), preconizaba que todo acto humano, norma o institución, debían ser juzgados según su utilidad. En Colombia, una vez Santander regresa al poder decide adoptar oficialmente las teorías de Bentham en los colegios y universidades, escandalizando con ello al clero. Así pues, la "lei orgánica de estudios del 18 de marzo de 1826 " y el "Decreto del poder ejecutivo dado en 3 de octubre de 1826 estableciendo el plan jeneral para el arreglo uniforme de la escuelas, colegios y universidades", hacían obligatorio el texto de Bentham sobre derecho internacional. 
Los ataques a su promulgación no se hicieron esperar y la situación patentizó la permanente pugna política por controlar los saberes que se impartían en la universidad ${ }^{24}$.

Las estructuras curriculares reflejaban entonces transformaciones y cambios que muchas veces daban cabida a nuevos planes de estudio, orientándose, desde ese momento, hacia las ciencias ${ }^{25}$. Con la Ley Orgánica de Universidades 1366, del 21 de mayo de 1842, se instaura un cambio en la estructura curricular. Promulgada por Mariano Ospina Rodríguez ${ }^{26}$ (1805-1885), entonces ministro de Instrucción Pública, la ley pretendía impartir una educación de corte útil y práctica y, sobre todo, menos memorística. Se les dio impulso a las ciencias naturales, principal objetivo en la tarea de formar profesionales que pudieran estimular el mercado internacional y, por consiguiente, el desarrollo económico del país. Fueron incentivados, además, los estudios hacia el comercio y la agricultura, buscando ampliar la oferta educativa, centrada hasta entonces en el derecho y la medicina ${ }^{27}$. El currículo se encontraba organizado, centralizado y fiscalizado por el Consejo de la universidad ${ }^{28}$. La idea de los créditos educativos apareció en este periodo, buscando que algunos cursos de ciertas instituciones, que estaban diseñados a la manera de créditos educativos, les fuesen homologados por las universidades ${ }^{29}$.

Para 1848, bajo el gobierno de Tomás Cipriano de Mosquera ${ }^{30}$ (1798-1878), se establece, mediante la ley 1842 del 8 de mayo de 1848, la Escuela de Ciencias Naturales, Físicas y Matemáticas de la Universidad de Bogotá, con lo cual se busca reorientar los planes de estudio hacia la creación de asignaturas como: "Hidráulica aplicada a la construcción de canales, Usos del vapor en la fuerza motriz, Aplicación del vapor a las máquinas, Construcción y administración de ferrovías, Botánica de la zona tórrida, Agricultura subtropical, Higiene para los trabajadores de las minas" ${ }^{\prime 3}$.

24 Javier Ocampo López, "Historiografía de la Universidad Republicana”, en Historia de la universidad colombiana, ed. Diana Soto Arango (Tunja: Universidad Pedagógica y Tecnológica de Colombia, 1998), 73-86.

25 Soto Arango, “Aproximación histórica", 16.

26 Mariano Ospina Rodríguez nació en Guasca, Cundinamarca. Doctor en Jurisprudencia en 1827, su primer cargo lo ocupó como rector de un colegio particular. En 1828 se vio envuelto en la llamada "conspiración septembrina", un complot para asesinar al libertador Simón Bolívar, lo que lo obligó a confinarse en Antioquia por varios años. Bajo la administración del gobierno de Pedro Alcántara Herrán (1841-1845), Ospina Rodríguez fue simultáneamente ministro de Gobierno, de Instrucción Pública y de Relaciones Exteriores; en los dos últimos años tuvo a su cargo los ministerios de Gobierno y de Instrucción Pública.

27 Arias de Greiff y Sánchez, “Antecedentes”, 19.

28 Soto Arango, "Aproximación histórica”, 16.

29 Evelyn Ahern, "El desarrollo de la educación en Colombia: 1820-1850”, Revista Colombiana de Educación n. ${ }^{\text {os }} 22-23$ (1991).

30 Tomás Cipriano de Mosquera y Arboleda fue una las figuras políticas más importantes del siglo XIX al ocupar cuatro veces la presidencia de la República de Colombia (1845, 1861, 1862 y 1866). Asimismo se desempeñó como representante a la Cámara (1834, 35 y 36), comandante militar de Bogotá y jefe de la primera división (1837), secretario de Guerra y Marina, encargado del despacho del Interior y de Relaciones Exteriores (1838-40), jefe de la primera división (1840), general en jefe del ejército (1841-42), ministro plenipotenciario en Perú, Chile y Bolivia. Con la disolución de la Gran Colombia, Mosquera tomó partido como bolivarista. En el ámbito educativo escribió varios artículos científicos y algunas obras sobre geografía de Colombia, la más importante de ellas Memoria sobre la geografia fisica y politica de la Nueva Granada. En 1848 instala el Instituto Caldas con el fin de fomentar la cultura y la investigación.

31 Ahern, "El desarrollo de la educación", 50. 
Para este momento, el estímulo a la educación en todos sus niveles se vio reflejada en la puesta en marcha de distintas instituciones como el Colegio Militar para ingenieros, la Academia de dibujo y pintura, la Escuela Práctica de Arquitectura y en "Popayán la primera cátedra de Química a cargo del profesor José Éboli venido de Europa"32. A su vez, con la presidencia de José Hilario López ${ }^{33}$ (1849-1853), se firma la Ley del Congreso del 15 de mayo de 1850 que, para la instrucción pública, otorga libertad de enseñanza en todos los niveles a la enseñanza de la ciencia y establece que no es necesario el grado de científico para ejercer la profesión, suprimiendo, además, el grado de bachiller por el otorgamiento de título de doctor en jurisprudencia, medicina y ciencias eclesiásticas $^{34}$.

Con el presidente Santos Acosta ${ }^{35}$ (1867-1868) se le da prevalencia para incidir sobre el sector educativo a José María Samper, quien presenta el proyecto de ley 66 de 1867 y crea la Universidad Nacional de los Estados Unidos de Colombia. Con esta nueva institución la estructura curricular asume, como principal objetivo, la promoción de la enseñanza de las ciencias, buscando impulsar, una vez más, el desarrollo científico del país ${ }^{36}$. Para ese momento, la Universidad Nacional de los Estados Unidos de Colombia contaba con seis escuelas o institutos: literatura y filosofía, medicina, derecho, ciencias naturales, ingeniería y el instituto de artes y oficios. Determina, además, que la Biblioteca Nacional, el Observatorio Astronómico y el Museo pasen a la escuela de ciencias naturales y, por ende, queden adscritos a la naciente universidad; a su vez, establece que a la escuela de medicina se adscriban el laboratorio químico, el hospital de caridad y el militar ${ }^{37}$.

Ahora bien, ya en el siglo XX, buscando otros rumbos para la educación, desde el Estado se cursa invitación a seis misiones académicas internacionales: Kemmerer (1923), Pedagógica Alemana (1924), Chardón (1929), Operación Colombia (1949), Economía para América Latina (1954), Economía y Humanismo en Colombia (1954), con el fin de realizar estudios diagnósticos en diferentes aspectos del acontecer nacional, ya que la discusión política vislumbraba escenarios que deberían ser cubiertos desde la universidad.

Fruto de las recomendaciones de las misiones académicas internacionales es el impulso a la creación de las universidades regionales: Universidad del

32 Ibíd., 51.

33 José Hilario López (1798-1869). Militar y político colombiano, oriundo de Popayán. Llega a la presidencia de Colombia en 1849 como candidato de los radicales. En su gobierno se suprimió la pena de muerte por delitos políticos, fue abolida la esclavitud y se establecieron el sufragio universal y la enseñanza gratuita y obligatoria.

34 "Sobre instrucción pública", Ley de 1850, 15 de mayo, Senado y Cámara de Representantes de la Nueva Granada (Secretaría Jurídica Distrital de la Alcaldía Mayor) f. 2. http://www.alcaldiabogota.gov.co/sisjur/normas/Norma1.jsp?i=12626

35 Manuel María de los Santos Acosta (1827-1901). Recibe el título de doctor en Medicina y Cirugía en 1851. Sus actividades políticas estuvieron enmarcadas en el liberalismo radical. En este camino fue diputado de Miraflores, primer designado de la gobernación de Tunja, representante a la Cámara, senador, asambleísta y presidente del Estado de Boyacá.

36 José Eliseo Baicué Peña, "Educación superior en un espacio de frontera: historia y desarrollo académico de la universidad Surcolombiana, 1970-2010" (tesis de maestría en Historia, Universidad Nacional de Colombia, 2009), 24.25.

37 "El Congreso de los Estados Unidos de Colombia" (1867), Sistema de Información Normativa, Jurisprudencial y de Conceptos (SINJC), Congreso, f. 1. 
Atlántico (1941), Universidad de Caldas (1943), Universidad del Tolima (1945), Universidad del Valle (1945), Universidad Industrial de Santander (1948), Universidad Tecnológica de Pereira (1958), Universidad del Quindío (1960), así como las seccionales de la Universidad Nacional en las ciudades de Medellín (1936), Palmira (1946) y Manizales (1948); universidades que deben su estructura curricular (programas, planes de estudio y organización) al impulso que el proceso de industrialización del país requería: " [...] la universidad del Estado es la que debe formar a los científicos, profesionales y técnicos que el país necesita desde el horizonte de la apertura a las ideas y al conocimiento; a base de libertad de cátedra, de organización y de investigación $[\ldots]^{\prime \prime 38}$.

\section{La Universidad del Tolima: hacia una discusión sobre el establecimiento de una estructura curricular}

Se crea la Universidad del Tolima mediante la Ordenanza n. ${ }^{\circ} 05$ de 1945, emitida por la Asamblea del Tolima: "Por la cual se crea en Ibagué la Universidad del Tolima y el fondo acumulativo de la misma". La convulsión política y económica del país posterga el inicio de sus actividades académicas hasta 1955. Varios son los motivos posibles de aducir: falta de presupuesto por parte del departamento, la división entre turbayistas y gaitanistas ${ }^{39}$ y la compleja situación civil generada por la muerte del caudillo Jorge Eliécer Gaitán ${ }^{40}$ en 1948, así como la negligencia de algunos sectores políticos ya que Ibagué, muy cerca de Bogotá, albergaba a muchos intelectuales e hijos de familias pudientes que se desplazaban a Bogotá para trabajar y estudiar ${ }^{41}$.

El teniente coronel César Augusto Cuéllar Velandia (1953-1955), oficiando como gobernador del departamento del Tolima, da apertura e inicio a las labores académicas propias de la Universidad del Tolima mediante la reforma de la Ordenanza de 1945, a través del Decreto de la Gobernación 1916 de 1954 (octubre 25), sancionada por medio del Decreto de la Gobernación 357 de 1955: "Por el cual se crean unos cargos, se fijan sus emolumentos y se dictan otras disposiciones relacionadas con la Universidad del Tolima".

38 Blanca Inés Ortiz, “Aproximación a la historiografía y fuentes de la Universidad Distrital Francisco José de Caldas”, en Historia de la universidad colombiana, ed. Diana Soto Arango (Tunja: Universidad Pedagógica y Tecnológica de Colombia, 1998), 179-191.

39 La campaña a la presidencia de la República de Colombia en 1946 tuvo dos candidatos por el partido liberal, Gabriel Turbay Avinader y Jorge Eliécer Gaitán. Los electores de ese partido se dividieron de manera violenta a nivel nacional, en lo que se llamó la contra-campaña. Turbay, de ancestros sirio-libaneses, fue catalogado como el candidato de las ideas comunistas y llamado antipatria, candidato de una facción o de una colonia de repugnantes extranjeros. Gaitán fue considerado el candidato de caudalosas fuerzas de choque, oscuras brigadas de asalto.

40 Jorge Eliécer Gaitán (1903-1948) fue un político, escritor y jurista bogotano que ocupó distintos cargos públicos como la alcaldía mayor de Bogotá, los ministerios de Educación y Trabajo, fue congresista y candidato a la presidencia de la República.

41 Néstor Hernando Parra Escobar, "La Universidad del Tolima y la reestructuración de la educación superior en Colombia", en Obras selectas de N. H. Parra, vol. 3: Educación y desarrollo humano (Ibagué: Universidad de Ibagué, 2013), 905-910. 
Tabla 1. Relación de los programas creados en la Universidad del Tolima entre 1955 y 1962

\begin{tabular}{|c|c|c|c|}
\hline n. ${ }^{\circ}$ & Programa & Acto administrativo & $\begin{array}{c}\text { Origen de sus } \\
\text { currículums }\end{array}$ \\
\hline 1 & $\begin{array}{l}\text { Facultad de } \\
\text { Agronomía }\end{array}$ & $\begin{array}{l}\text { Decreto } 357 \text { de } 1955 \text { (marzo 10), } \\
\text { Gobernación. "Por el cual se } \\
\text { crean unos cargos, se fijan sus } \\
\text { emolumentos y se dictan otras } \\
\text { disposiciones relacionadas con la } \\
\text { Universidad del Tolima" }\end{array}$ & $\begin{array}{l}\text { Universidad Nacional } \\
\text { de Palmira }\end{array}$ \\
\hline 2 & Pintura & $\begin{array}{l}\text { Decreto } 199 \text { de } 1956 \text { (enero 31), } \\
\text { Gobernación. "Por el cual se anexa la } \\
\text { Escuela de Bellas Artes" }\end{array}$ & $\begin{array}{l}\text { Aprobación: Director } \\
\text { de Educación } \\
\text { Nacional }\end{array}$ \\
\hline 3 & Escultura & Decreto 199 de 1956 (enero 31) & $\begin{array}{l}\text { Aprobación: Director } \\
\text { de Educación } \\
\text { Nacional } \\
\end{array}$ \\
\hline 4 & Cerámica & Decreto 199 de 1956 (enero 31) & $\begin{array}{l}\text { Aprobación: Director } \\
\text { de Educación } \\
\text { Nacional }\end{array}$ \\
\hline 5 & $\begin{array}{l}\text { Decorado y } \\
\text { Dibujo }\end{array}$ & Decreto 199 de 1956 (enero 31) & $\begin{array}{l}\text { Aprobación: Director } \\
\text { de Educación } \\
\text { Nacional }\end{array}$ \\
\hline 6 & $\begin{array}{l}\text { Escuela de } \\
\text { Topografía }\end{array}$ & $\begin{array}{l}\text { Acuerdo } 01 \text { de } 1961 \text { (enero 26), } \\
\text { Consejo Superior. Se crea el Instituto } \\
\text { Politécnico: Escuela de Topografía, } \\
\text { Escuela de Auxiliares de Enfermería } \\
\text { y Escuela de Técnicos Electricistas } \\
\end{array}$ & $\begin{array}{l}\text { Fondo Universitario } \\
\text { Nacional. Acuerdo } 18 \\
\text { de } 1960\end{array}$ \\
\hline 7 & $\begin{array}{l}\text { Escuela de } \\
\text { Auxiliares de } \\
\text { Enfermería }\end{array}$ & Acuerdo 01 de 1961 (enero 26) & $\begin{array}{l}\text { Plan de estudios del } \\
\text { servicio cooperativo } \\
\text { Interamericano de } \\
\text { Salud Pública }\end{array}$ \\
\hline 8 & \begin{tabular}{|l|} 
Escuela de \\
Técnicos \\
Electricistas \\
\end{tabular} & Acuerdo 01 de 1961 (enero 26) & \\
\hline 9 & \begin{tabular}{|l|} 
Facultad de \\
Medicina \\
Veterinaria y \\
Zootecnia \\
\end{tabular} & $\begin{array}{l}\text { Acuerdo } 05 \text { de } 1961 \text { (junio 5), Consejo } \\
\text { Superior. "Por el cual se crean otras } \\
\text { facultades" }\end{array}$ & $\begin{array}{l}\text { Ministerio de Educa- } \\
\text { ción Nacional }\end{array}$ \\
\hline 10 & $\begin{array}{l}\text { Facultad de } \\
\text { Ingeniería } \\
\text { Forestal }\end{array}$ & Acuerdo 05 de 1961 (junio 5) & \begin{tabular}{|l} 
Acuerdo 014 de \\
febrero 7 de 1962, \\
Consejo Directivo de \\
la Universidad del \\
Tolima
\end{tabular} \\
\hline
\end{tabular}

Fuente: Elaboración propia con base en la Oficina de Archivo de la Universidad del Tolima. 
Como se puede ver en la tabla 1, la Facultad de Agronomía, creada mediante Decreto 357 de 1955 expedido por el gobernador del departamento, fue abierta bajo el mandato del teniente coronel César Augusto Cuéllar Velandia ${ }^{42}$. La Escuela Agronómica San Jorge, de la orden de los salesianos, fue la primera, no solo de la Facultad de Agronomía, también del alma mater; la Facultad de Agronomía aprovechó muy bien el terreno constituido por sesenta hectáreas aptas para los requerimientos de las prácticas de campo ${ }^{43}$.

La estructura curricular asumida y los planes de estudios instaurados se incorporan tomando como base algunos planes de estudios de la Universidad de Palmira, atendiendo a lo reglamentado por el Decreto 260 de $1936^{44}$, que establecía que las universidades públicas y privadas debían acogerse en lo relacionado a "programas y planes de enseñanza" a los establecidos por la Universidad Nacional; así mismo, mediante el Decreto 0701 de $1954^{45}$, que reglamentó el ejercicio de la Ingeniería Agronómica.

El plan de estudios se organizó de la siguiente manera: un año previo, dividido en dos semestres, haciendo énfasis en un gran componente de asignaturas propias de las ciencias básicas - ocho en cada semestre-. Del primero al cuarto año, se establecieron dos grandes componentes para la enseñanza: el profesional ( $40 \%$ ) y el disciplinar (21,66 \%), incluido un banco de asignaturas electivas, integrado por cuatro áreas: Biología, Fitotecnia, Zootecnia General y Economía y Ciencias Sociales. Este plan de estudios no evidencia la presencia de espacios para la enseñanza de asignaturas de corte humanista; la tesis para obtener el título, por su parte, estaba incluida dentro del plan de estudios y contaba con una asignación de una hora a la semana, a lo largo del último año de estudios.

42 Una vez terminada la guerra de los Mil Días (1899-1902), el Ministerio de Educación Nacional inicia la reconstrucción orgánica de la universidad colombiana a través de una serie de leyes y decretos que van a regular la vida tanto pública como privada de esa institución. Grosso modo, se establece una nueva ley orgánica para la Universidad Nacional, sobre el ingreso a las "Facultades Universitarias", organización de la educación técnica, formación del profesorado para las Escuelas Normales Universitarias, normas para la fundación y funcionamiento de establecimientos universitarios, entre otras. Como para aquel momento los recursos naturales ya se habían convertido en un elemento vital para la economía de la nación, el Estado colombiano regula su uso y aprovechamiento a través del Decreto 0701 del 5 de marzo de 1954 "Sobre el ejercicio de la profesión de Ingeniería Agronómica".

43 José María Mosquera, "Apuntes para una historia de la Facultad de Ingeniería Agronómica de la Universidad del Tolima”, Revista Avance y Desarrollo n. $^{\circ} 1$ (1989): 22-34.

44 El decreto contiene tres artículos que regulan y someten a inspección a las universidades, no solo oficiales sino privadas, dejando claro que se deben sujetar a los planes de estudio y tener la "dotación material científica y pedagógica" de la Universidad Nacional; en cuanto a los reglamentos, serían tenidos en cuenta los que expidiera el MEN, el Departamento Nacional de Higiene y la Comisión Nacional de Educación Física, además de aceptar la inspección oficial.

45 Sancionado por el gobierno militar del general Rojas, esta disposición administrativa determina que es el Estado el que debe velar por el buen manejo y conservación del suelo, la flora, la fauna y el agua como patrimonio nacional. Consta de nueve artículos, mediante los cuales se le otorga todo el respaldo al ejercicio de la Ingeniería Agronómica para ser una profesión con función social. La norma establece quiénes podrían ejercer la profesión en el territorio colombiano, teniendo a su cargo las labores de enseñanza, investigación, de fomento, extensión y los casos de peritazgo; para hacer efectivo lo anterior se creó el Consejo Profesional Agronómico y la tarjeta profesional. 
Tabla 2. Plan de estudios de la Facultad de Agronomía de la Universidad

Nacional, sede Palmira del año de 1954, que sirvió de modelo para el programa de la Facultad de Agronomía de la Universidad del Tolima.

\begin{tabular}{|c|c|c|c|c|c|c|c|}
\hline \multicolumn{8}{|c|}{ AÑO PREVIO } \\
\hline Semestre & Asignatura & $\begin{array}{c}\text { Horas } \\
\text { teóricas }\end{array}$ & $\begin{array}{c}\text { Horas } \\
\text { prácticas }\end{array}$ & Semestre & Asignatura & $\begin{array}{c}\text { Horas } \\
\text { teóricas }\end{array}$ & $\begin{array}{c}\text { Horas } \\
\text { prácticas }\end{array}$ \\
\hline \multirow{9}{*}{ I } & Aritmética & 3 & 1 & \multirow{9}{*}{ II } & $\begin{array}{l}\text { Trigonome- } \\
\text { tría }\end{array}$ & 3 & 0 \\
\hline & Álgebra I & 4 & 0 & & Álgebra II & 4 & 0 \\
\hline & $\begin{array}{l}\text { Geometría } \\
\text { plana }\end{array}$ & 3 & 0 & & $\begin{array}{l}\text { Geometría del } \\
\text { espacio }\end{array}$ & 4 & 0 \\
\hline & Física I & 4 & 1 & & Física II & 4 & 1 \\
\hline & Química I & 3 & 2 & & Química II & 3 & 3 \\
\hline & \begin{tabular}{|l|} 
Dibujo \\
\end{tabular} & 0 & 4 & & Dibujo & 0 & 4 \\
\hline & Inglés & 2 & 0 & & Inglés & 2 & 0 \\
\hline & $\begin{array}{l}\text { Propagación } \\
\text { de plantas }\end{array}$ & 2 & 3 & & Zootecnia I & 3 & 3 \\
\hline & \begin{tabular}{|l|}
$\begin{array}{l}\text { Total horas } \\
\text { semanales }\end{array}$ \\
\end{tabular} & 21 & 11 & & \begin{tabular}{|l|}
$\begin{array}{l}\text { Total horas } \\
\text { semanales }\end{array}$ \\
\end{tabular} & 23 & 11 \\
\hline \multicolumn{8}{|c|}{ PRIMER AÑO } \\
\hline \multirow{8}{*}{ III } & Biología & 2 & 3 & \multirow{8}{*}{ IV } & Zoología & 2 & 3 \\
\hline & Topografía & 2 & 3 & & Agrimensura & 2 & 3 \\
\hline & Geología & 3 & 3 & & Horticultura & 2 & 3 \\
\hline & $\begin{array}{l}\text { Maquinaria y } \\
\text { talleres }\end{array}$ & 2 & 4 & & $\begin{array}{l}\text { Maquinaria y } \\
\text { talleres }\end{array}$ & 2 & 4 \\
\hline & Química III & 2 & 3 & & Química IV & 2 & 3 \\
\hline & $\begin{array}{l}\text { Cálculo } \\
\text { diferencial }\end{array}$ & 3 & 0 & & $\begin{array}{l}\text { Cálculo } \\
\text { integral }\end{array}$ & 3 & 0 \\
\hline & \begin{tabular}{|l|}
$\begin{array}{l}\text { Total horas } \\
\text { semanales }\end{array}$ \\
\end{tabular} & 14 & 16 & & \begin{tabular}{|l|}
$\begin{array}{l}\text { Total horas } \\
\text { semanales }\end{array}$ \\
\end{tabular} & 13 & 16 \\
\hline & Total horas & 30 & & & Total horas & 29 & \\
\hline \multicolumn{8}{|c|}{ SEGUNDO AÑO } \\
\hline \multirow{7}{*}{ V } & $\begin{array}{l}\text { Botánica } \\
\text { general }\end{array}$ & 3 & 3 & \multirow{7}{*}{ VI } & \begin{tabular}{|l|} 
Botánica \\
taxonómica
\end{tabular} & 1 & 3 \\
\hline & Suelos I & 3 & 3 & & Suelos II & 3 & 3 \\
\hline & Economía I & 3 & 0 & & Economía II & 3 & 0 \\
\hline & Hidráulica & 3 & 3 & & \begin{tabular}{|l|} 
Riegos, \\
avenamientos \\
\end{tabular} & 2 & 2 \\
\hline & Bacteriología & 3 & 3 & & Zootecnia II & 3 & 3 \\
\hline & \begin{tabular}{|l|}
$\begin{array}{l}\text { Total horas } \\
\text { semanales }\end{array}$ \\
\end{tabular} & 15 & 12 & & \begin{tabular}{|l|}
$\begin{array}{l}\text { Total horas } \\
\text { semanales }\end{array}$ \\
\end{tabular} & 12 & 11 \\
\hline & Total horas & 27 & & & Total horas & 32 & \\
\hline
\end{tabular}


Universidad del Tolima (1955 a 1962)

\begin{tabular}{|c|c|c|c|c|c|c|c|}
\hline \multicolumn{8}{|c|}{ TERCER AÑO } \\
\hline \multirow{7}{*}{ VII } & Genética & 3 & 3 & \multirow{7}{*}{ VIII } & $\begin{array}{l}\text { Análisis } \\
\text { estadístico }\end{array}$ & 3 & 3 \\
\hline & Cultivos I & 3 & 3 & & Cultivos II & 3 & 3 \\
\hline & Entomología I & 3 & 3 & & $\begin{array}{l}\text { Entomología } \\
\text { II }\end{array}$ & 3 & 3 \\
\hline & $\begin{array}{l}\text { Construcciones } \\
\text { rurales }\end{array}$ & 2 & 3 & & $\begin{array}{l}\text { Administra- } \\
\text { ción rural }\end{array}$ & 2 & 3 \\
\hline & \begin{tabular}{|l|} 
Electiva \\
\end{tabular} & 3 & 3 & & Electiva & 3 & 3 \\
\hline & \begin{tabular}{|l|}
$\begin{array}{l}\text { Total horas } \\
\text { semanales }\end{array}$ \\
\end{tabular} & 14 & 15 & & $\begin{array}{l}\text { Total horas } \\
\text { semanales }\end{array}$ & 14 & 15 \\
\hline & Total horas & 29 & & & Total horas & 29 & \\
\hline \multicolumn{8}{|c|}{ CUARTO AÑO } \\
\hline \multirow{8}{*}{ IX } & \begin{tabular}{|l} 
Fitomejora- \\
miento
\end{tabular} & 3 & 3 & \multirow{8}{*}{$x$} & Mercados & 3 & 0 \\
\hline & Micología & 3 & 3 & & Fitopatología & 3 & 3 \\
\hline & $\begin{array}{l}\text { Control de } \\
\text { plagas }\end{array}$ & 2 & 3 & & $\begin{array}{l}\text { Control de } \\
\text { enfermedades }\end{array}$ & 2 & 3 \\
\hline & Cultivos III & 3 & 3 & & Zootecnia III & 2 & 3 \\
\hline & \begin{tabular}{|l|} 
Electiva \\
\end{tabular} & 3 & 3 & & Electiva & 3 & 3 \\
\hline & $\begin{array}{l}\text { Tesis y } \\
\text { seminario }\end{array}$ & 1 & 0 & & $\begin{array}{l}\text { Tesis y } \\
\text { seminario }\end{array}$ & 1 & 0 \\
\hline & \begin{tabular}{|l|}
$\begin{array}{l}\text { Total horas } \\
\text { semanales }\end{array}$ \\
\end{tabular} & 15 & 15 & & $\begin{array}{l}\text { Total horas } \\
\text { semanales }\end{array}$ & 14 & 12 \\
\hline & Total horas & 30 & & & Total horas & 26 & \\
\hline
\end{tabular}

Fuente: Facultad de Agronomía. Elaboración propia con base en el Anuario Universidad de Palmira (Palmira: 1954).

Mediante el Decreto 199 de 1956, expedido por el gobernador del departamento, se anexa a esta naciente universidad regional la Escuela de Bellas Artes, conservando los mismos cuatro programas o "secciones": Pintura, Escultura, Cerámica, Decorado y Dibujo. Su plan de estudios fue elaborado por el director del instituto, el padre Pedro José Ramírez Sendoya, y aprobado por el Director de Educación Nacional.

El Consejo Superior de la Universidad del Tolima, por Acuerdo 01 de 1961, crea el Instituto Politécnico con tres secciones: Escuela de Topografía, Escuela de Auxiliares de Enfermería y Escuela de Técnicos Electricistas. El plan de estudios de la Escuela de Topografía fue aprobado por el Comité Administrativo del Fondo Nacional, mediante el Acuerdo 18 de 1960 y, por su parte, el plan de estudios de la Escuela de Enfermería fue autorizado por el Servicio Cooperativo Interamericano de Salud Pública.

Para 1955 se organizan dos facultades del área agropecuaria: Medicina Veterinaria y Zootecnia e Ingeniería Forestal, mediante el Acuerdo 05 de 1961, emitido por el Consejo Superior, siendo rector Néstor Hernando Parra ${ }^{46}$. Con el

46 Rafael Iván Montoya, “Reseña histórica de la Facultad de Medicina Veterinaria y Zootecnia”, Revista Avance y Desarrollo n. 1 (1989): 66-67. 
Acuerdo n. ${ }^{\circ}$ 010, del 17 de abril y el Acuerdo n. ${ }^{\circ}$ 075, del 4 de diciembre de 1964, son aprobados los tres primeros años de la Facultad de Medicina Veterinaria y Zootecnia y, mediante el Acuerdo n. ${ }^{\circ}$ 031, de julio 14 de 1965, se da vía libre para el funcionamiento del séptimo y octavo semestres. Con la Resolución n. ${ }^{\circ}$ 0977, de abril 17 de 1967, emitida por el Ministerio de Educación Nacional, se aprueban el noveno y décimo semestres.

La Facultad de Ingeniería Forestal se crea luego del "Primer Seminario de la Enseñanza de la Ingeniería Agronómica, Forestal y Medicina Veterinaria y Zootecnia", realizado en Ibagué en 1961 y por recomendación de la Asociación Colombiana de Universidades (ASCUN); Su plan de estudios se enfocaría a la Silvicultura y la conservación de suelos y aguas. Adopta el plan de estudios mediante el Acuerdo 014, de 1962, emitido por el Consejo Directivo de la Universidad del Tolima. Este plan de estudios de la Facultad de Ingeniería Forestal fue gestado y aprobado gracias a trabajo de un grupo de profesores vinculados a la Universidad del Tolima.

Este plan de estudios se organizó en cinco años; cada año se cursaban dos semestres con un promedio de treinta y tres horas semanales de clase y una presencia de entre seis y nueve materias. En los dos primeros semestres se debían cursar el más alto número de asignaturas, inclinándose hacia el área de las básicas (Física, Química y Biología). Así mismo, el plan de estudios deja ver la inclinación hacia la formación en Silvicultura y la conservación de suelos y aguas, como lo solicitara el acuerdo de creación ${ }^{47}$.

A su vez, el plan de estudios de la Facultad de Ingeniería Forestal también fue organizado cinco años, como ordenaba la legislación del caso, con un 74,16 \% del componente profesional; en cuanto al componente disciplinar, un 24,01 \%, y con 1,82 \% para el componente humanístico. Una vez culminado el plan de estudios, era requisito para titularse haber sustentado y aprobado la tesis de grado y poseer "los conocimientos suficientes del idioma inglés para traducir literatura científica forestal" ${ }^{\prime 4}$.

47 "Por el cual se adopta el plan de estudios para la carrera de Ingeniería Forestal", Oficina de Archivo de la Universidad del Tolima (OAUT), Consejo Directivo, f. 3.

48 Ibíd. 
Tabla 3. Plan de estudios de la Facultad de Ingeniería Forestal de 1962, Acuerdo del Consejo Directivo 014 (febrero 7) de 1962.

\begin{tabular}{|c|c|c|c|c|c|}
\hline \multicolumn{6}{|c|}{ PRIMER AÑO } \\
\hline Semestre & Asignaturas & $\begin{array}{c}\text { Horas } \\
\text { semanales }\end{array}$ & Semestre & Asignaturas & $\begin{array}{l}\text { Horas } \\
\text { sema- } \\
\text { nales }\end{array}$ \\
\hline \multirow{10}{*}{ I } & $\begin{array}{l}\text { Análisis Algebraico } \\
\text { (Aritmética, Analítica y } \\
\text { Álgebra, integradas) }\end{array}$ & 5 & \multirow{10}{*}{ II } & $\begin{array}{l}\text { Análisis } \\
\text { Algebraico } \\
\text { (Álgebra y } \\
\text { Trigonometría, } \\
\text { integradas) } \\
\end{array}$ & 5 \\
\hline & Biología y laboratorio & 6 & & $\begin{array}{l}\text { Botánica } \\
\text { general }\end{array}$ & 6 \\
\hline & Castellano & 2 & & Castellano & 2 \\
\hline & $\begin{array}{l}\text { Dibujo técnico I y } \\
\text { Geometría descriptiva I }\end{array}$ & 4 & & $\begin{array}{l}\text { Dibujo técnico } \\
\text { II y Geometría } \\
\text { descriptiva II }\end{array}$ & 4 \\
\hline & Geometría plana & 3 & & $\begin{array}{l}\text { Geometría del } \\
\text { espacio }\end{array}$ & 3 \\
\hline & Humanidades & 4 & & $\begin{array}{l}\text { Inglés técnico } \\
\text { forestal }\end{array}$ & 4 \\
\hline & Nociones de Dasonomía & 2 & & \begin{tabular}{|l|}
$\begin{array}{l}\text { Orientación } \\
\text { profesional }\end{array}$ \\
\end{tabular} & 2 \\
\hline & Química general & 4 & & $\begin{array}{l}\text { Química } \\
\text { inorgánica }\end{array}$ & 6 \\
\hline & $\begin{array}{l}\text { Viveros forestales I. } \\
\text { (Silvicultura I) }\end{array}$ & 5 & & \begin{tabular}{|l|} 
Viveros \\
forestales II \\
(Silvicultura II) \\
\end{tabular} & 3 \\
\hline & Total & 35 & & Total & 35 \\
\hline \multicolumn{6}{|c|}{ SEGUNDO AÑO } \\
\hline \multirow{7}{*}{ III } & Análisis matemático & 3 & \multirow{7}{*}{ IV } & $\begin{array}{l}\text { Análisis } \\
\text { matemático }\end{array}$ & 3 \\
\hline & Botánica taxonómica & 6 & & Dendrología I & 5 \\
\hline & Física I & 6 & & Física II & 6 \\
\hline & Geología & 6 & & $\begin{array}{l}\text { Meteorología y } \\
\text { climatología }\end{array}$ & 5 \\
\hline & Química orgánica & 6 & & Piscicultura & 3 \\
\hline & Topografía I & 5 & & Topografía II & 5 \\
\hline & Total & 32 & & Zoología & 5 \\
\hline & & & & Total & 32 \\
\hline
\end{tabular}




\begin{tabular}{|c|c|c|c|c|c|}
\hline \multicolumn{6}{|c|}{ TERCER AÑO } \\
\hline \multirow{7}{*}{$\mathrm{V}$} & Dendrología II & 5 & \multirow{7}{*}{ VI } & \begin{tabular}{|l} 
Análisis \\
Estadístico
\end{tabular} & 4 \\
\hline & Entomología forestal & 6 & & \begin{tabular}{|l|} 
Ecología \\
forestal \\
\end{tabular} & 6 \\
\hline & $\begin{array}{l}\text { Estática de construc- } \\
\text { ciones }\end{array}$ & 5 & & Hidráulica & 6 \\
\hline & Fisiología vegetal & 6 & & \begin{tabular}{|l} 
Maquinaria y \\
taller forestales \\
II
\end{tabular} & 5 \\
\hline & $\begin{array}{l}\text { Maquinaria y taller } \\
\text { forestales I }\end{array}$ & 5 & & \begin{tabular}{|l|}
$\begin{array}{l}\text { Mensuración } \\
\text { forestal I }\end{array}$ \\
\end{tabular} & 6 \\
\hline & Suelos I & 6 & & Suelos II & 6 \\
\hline & Total & 33 & & Total & 33 \\
\hline \multicolumn{6}{|c|}{ CUARTO AÑ̃ } \\
\hline \multirow{7}{*}{ VII } & Aerofotogrametría & 6 & \multirow{7}{*}{ VIII } & $\begin{array}{l}\text { Aprovecha- } \\
\text { miento de } \\
\text { bosques } \\
\end{array}$ & 6 \\
\hline & Anatomía de maderas & 6 & & $\begin{array}{l}\text { Construcciones } \\
\text { de transporte } \\
\text { forestal }\end{array}$ & 7 \\
\hline & $\begin{array}{l}\text { Construcción de muros y } \\
\text { represas }\end{array}$ & 6 & & $\begin{array}{l}\text { Mensuración } \\
\text { forestal II }\end{array}$ & 6 \\
\hline & Fauna silvestre & 3 & & $\begin{array}{l}\text { Protección } \\
\text { forestal }\end{array}$ & 4 \\
\hline & Fitopatología forestal & 6 & & Silvicultura II & 5 \\
\hline & $\begin{array}{l}\text { Resistencia de materiales } \\
\text { de construcción }\end{array}$ & 5 & & $\begin{array}{l}\text { Utilización } \\
\text { de tierras y } \\
\text { conservación de } \\
\text { suelos } \\
\end{array}$ & 4 \\
\hline & Total & 32 & & Total & 32 \\
\hline \multicolumn{6}{|c|}{ QUINTO AÑ̃O } \\
\hline \multirow{8}{*}{ IX } & $\begin{array}{l}\text { Economía forestal y } \\
\text { cooperativismo }\end{array}$ & 5 & \multirow{8}{*}{$X$} & $\begin{array}{l}\text { Administración } \\
\text { y política } \\
\text { forestales }\end{array}$ & 3 \\
\hline & $\begin{array}{l}\text { Elementos de extensión } \\
\text { forestal }\end{array}$ & 3 & & $\begin{array}{l}\text { Construcciones } \\
\text { para industrias } \\
\text { forestales } \\
\end{array}$ & 6 \\
\hline & Física de maderas & 6 & & $\begin{array}{l}\text { Ética profe- } \\
\text { sional }\end{array}$ & 2 \\
\hline & Legislación forestal & 3 & & $\begin{array}{l}\text { Ordenación y } \\
\text { valoración de } \\
\text { bosques } \\
\end{array}$ & 8 \\
\hline & Química de maderas & 5 & & Silvicultura IV & 5 \\
\hline & \begin{tabular}{|l|} 
Regulación de corrientes \\
fluviales
\end{tabular} & 6 & & \begin{tabular}{|l|}
$\begin{array}{l}\text { Tesis y semina- } \\
\text { rios }\end{array}$ \\
\end{tabular} & 2 \\
\hline & Silvicultura III & 5 & & $\begin{array}{l}\text { Utilización } \\
\text { industrial de } \\
\text { productos } \\
\text { forestales } \\
\end{array}$ & 6 \\
\hline & Total & 33 & & Total & 32 \\
\hline
\end{tabular}

Fuente: Elaboración propia con base en la Oficina de Archivo de la Universidad del Tolima. 
Ahora bien, de conformidad con el Acuerdo 010 de 1962, expedido por el Consejo Superior de la Universidad del Tolima, en su capítulo V, artículo 27, se establece como unidad académica el Instituto Superior de Bellas Artes, con las escuelas de: Delineantes de Arquitectura, Escultura y Pintura, Arte y Decoración y Artes Aplicadas. De esta manera, la Escuela de Bellas Artes pasa a ser Instituto $^{49}$.

Diagrama 1. Estructura curricular de la Universidad del Tolima para el año de 1962.

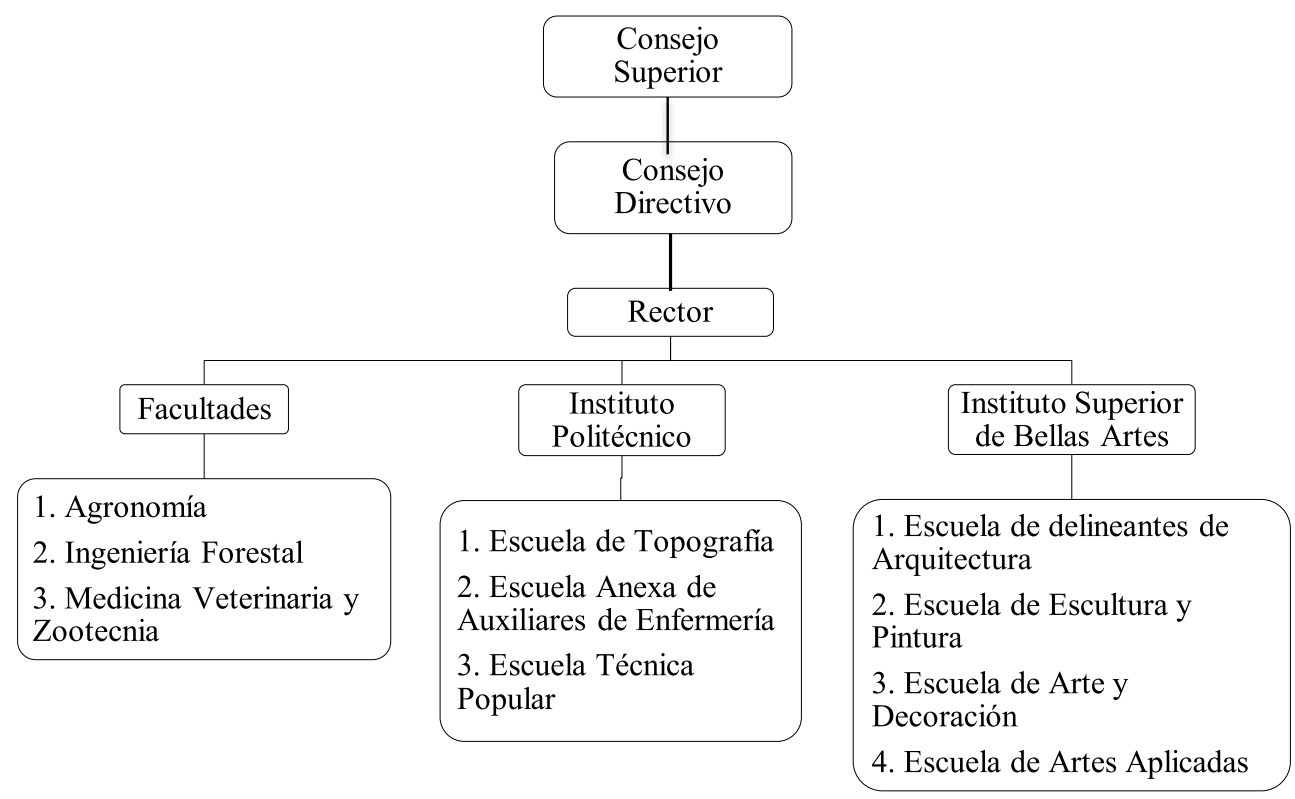

Fuente: Elaboración propia.

\section{CONCLUSIONES}

El estudio permite presentar un esbozo del proceso de institucionalización de la Universidad del Tolima, en el marco de las disposiciones nacionales de reorganización, por parte del Estado, de lo atinente al nivel universitario. Para el periodo de análisis, la estructura organizativa de la universidad se organiza y establece gracias a tres instancias: la primera, con las entidades que ayudan a regular la estructura universitaria, como el Instituto Colombiano de Especialización Técnica en el Exterior (ICETEX) ${ }^{50}$ (1950); la segunda, mediante el

49 "Por el cual se expide el Estatuto Orgánico de la Universidad del Tolima", OAUT, Consejo Superior, f. 31.

50 "Por el cual se crea el Instituto Colombiano de Especialización Técnica en el Exterior", Portal del Ministerio de Educación Nacional (PMEN), Presidente, f. 6. http://www.mineducacion.gov.co/1621/articles-103405_archivo_pdf.pdf 
Fondo Universitario Nacional (FUN) ${ }^{51}(1954)$ y, la tercera gracias a la Asociación Colombiana de Universidades (ASCUN) ${ }^{52}$ (1957).

Si bien es cierto que a través de la junta militar de 1957 fueron sancionados actos legislativos y administrativos conducentes a reestructurar la universidad pública, es también cierto que da paso a la creación de nuevas universidades, como la del Tolima.

Ahora bien, una veta de análisis promisoria es la establecida por el estudio de las misiones académicas internacionales invitadas al país a realizar estudios que "permitieran establecer medidas para avanzar en las necesidades profesionales del país"53. En sus diagnósticos, los informes Currie ${ }^{54}$ y Lebret ${ }^{55}$ coincidieron $^{\prime \prime}$ en la necesidad de "capacitar a la fuerza campesina", de tal manera que no sintiera "la necesidad de migrar a la ciudad"; para ello propusieron buscar el mejoramiento de la técnica agrícola. Proponen, también, mejorar los servicios de las facultades de Agronomía y de los Colegios Agrícolas, entregándosele al Estado la potestad de "organizar, administrar y orientar la educación del país" En cuanto a la educación industrial ${ }^{57}$, los informes consideran que se debe dar mayor impulso a la creación de establecimientos educativos, que en poco tiempo aumentarían la productividad económica del país ${ }^{58}$.

Fruto de estas recomendaciones, la estructura curricular de la Universidad del Tolima en el periodo analizado se asume conforme a los direccionamientos estatales: formación de profesionales del campo agropecuario y técnicos. Por

51 "Por el cual se provee el desarrollo de las universidades colombianas", PMEN, Presidente, f. 2. http://www.mineducacion.gov. co/1621/articles-103342_archivo_pdf.pdf

52 Carlos Alberto Molina Rodríguez, “1958, La Asociación Colombiana de Universidades: un interés gremial”, en $F U N-A S C U$ en la historia del sistema universitario colombiano, 1958-1968, eds. Carlos Alberto Molina Rodríguez (Bucaramanga: UIS, 2013), 161-200.

53 Omar Gómez, Sergio Gómez e Idilio Urrego, "La educación en Colombia en el siglo XX. 1900 - 1980" (tesis de maestría en Educación, Universidad de Antioquia, 1982), 264. 267. 269. 270.

54 Lauchlin Bernard Currie (1902-1993). Economista canadiense, nacionalizado colombiano, trabajó en la planeación y puesta en marcha del "New Deal" del gobierno de Roosevelt. Llega al país en 1949 como jefe de la primera "Misión del Banco Mundial". Para esos años Colombia se debatía entre los muertos dejados por el Bogotazo, las ruinas económicas y la falta de profesionales en el área de la economía que dieran respuesta a las necesidades apremiantes para el país: ferrocarriles, puertos, energía eléctrica, entre otros. El objetivo de Currie fue formular una política coherente de pensamiento para generar pleno empleo de la fuerza laboral y el crecimiento acelerado de la economía colombiana. Dos de sus obras: "Operación Colombia" y "Desarrollo Económico Acelerado".

55 Louis-Joseph Lebret (1897-1966). Economista y religioso francés de la orden de los dominicos. En 1941 funda en Francia el Centro de Economía y Humanismo, con el interés de unir la investigación con lo que llamó "militantes comprometidos con problemas prácticos". Esta experiencia se expandió a otros países como Alemania, Suiza, Suecia, Holanda y Brasil, donde realizó cerca de cien encuestas económicas y sociales. En 1947 Lebret llegó a Brasil para realizar trabajos sobre Economía Humana. En 1954 fue contactado por el presidente, general Gustavo Rojas Pinilla, para realizar un estudio sobre las condiciones de desarrollo del país.

56 Organización de Estados Iberoamericanos para la Educación, la Ciencia y la Cultura/MEN/ICETEX, "Sistemas Educativos Nacionales - Colombia", 1993. https://www.google.es/url?sa=t\&rct=j\&q=\&esrc=s\&source=web\&cd=1\&ved=2ahUKEwiZ2JLE79noAhWknuAKHStPAn0QFjAAegQIAhAB\&url=https\%3A\%2F\%2Fwww.oei.es\%2Fhistorico\%2Fquipu\%2Fcolombia\%2Fcol02.pdf\&usg=AOvVaw32nW0B8Qed3aR-IRuXIh4q (14/02/2017).

57 Este tipo de formación fue reglamentada mediante Ley 143 de 1948 (diciembre 23), "Por el cual se organiza la educación técnica", sancionada por el presidente Mariano Ospina Pérez. De sus 25 artículos, el primero deja claro a qué se refiere la enseñanza técnica: "La enseñanza técnica comprende la parte esencialmente práctica de la educación destinada a orientar hacia el trabajo racionalizando toda ocupación o actividad que no necesite de una cultura general académica. Queda en estos términos señalado el objeto de tal enseñanza". La Ley determinaba que la enseñanza técnica solo podía impartirse en las Escuelas de Aprendizaje, las Escuelas de Capacitación Obrera, Escuelas de Artes y Oficios, Institutos Técnicos, Facultades Técnicas y Universidades Técnicas. Los cursos estarían orientados hacia las ramas: técnicas industriales, actividades agrícolas, técnicas comerciales y ocupaciones para el hogar, esta última destinada a la mujer como "encargada de la economía doméstica". Generalmente los institutos son poseedores de una gran autonomía y tienen sus propias formas de funcionamiento administrativo y financiero.

58 Gómez, Gómez y Urrego, "La educación en Colombia”, 260. 
esta razón, se crean tres facultades que corresponderán a los programas agropecuarios de nivel profesional: Agronomía, Medicina Veterinaria y Zootecnia y Forestal. De igual manera, dos institutos de nivel tecnológico: el Politécnico - con tres escuelas - y el Superior de Bellas Artes - con cuatro escuelas - .

La Universidad del Tolima asumió la formación superior en el marco de la implementación de sus programas, mediante la importación de los planes de estudio para los primeros programas, como lo estableciera el Decreto 260 de 1936: "[...] se deben sujetar a los planes de estudio y tener la dotación material científica y pedagógica de la Universidad Nacional". Solo desde 1962 el plan de estudios currículum de Ingeniería Forestal se convierte en el primero que nace de la criba del cuerpo profesoral activo en la Universidad del Tolima, enfatizando el estudio de la Silvicultura y la apropiación de los recursos hídricos y del suelo.

La investigación permitió vislumbrar que, al no existir una planeación organizativa, las facultades, los institutos y las escuelas fueron surgiendo gracias al trabajo de los docentes que estructuraban e impartían las asignaturas. Así mismo, los documentos consultados no permiten entrever espacios de discusión sobre la organización y funcionamiento de los planes de estudio, ni escenarios para una discusión sobre las disciplinas ${ }^{59}$, aspecto que requiere esfuerzos académicos y mayores desarrollos investigativos.

Para finalizar, el análisis acerca de la universidad y el currículo permite conocer y comprender la lógica de funcionamiento de universidad y sus procesos de enseñanza. La necesidad de estudios acerca de cómo fue institucionalizada la Universidad del Tolima lleva a comprender que el currículo es posible pensarlo como un escenario de investigación que permite comprender los vínculos entre la sociedad y la universidad, así como entre la universidad y la sociedad ${ }^{60}$.

\section{FUENTES}

Congreso de los Estados Unidos de Colombia. Sistema de información Normativa, Jurisprudencial y de Conceptos "Régimen Legal" - Universidad Nacional de Colombia, Bogotá - Colombia. Congreso, f. 2. http://www.legal.unal.edu.co/sisjurun/normas/Norma1.jsp?i=34584

“Orgánica de la Universidad Nacional”. Biblioteca Virtual Colombiana (BVC), Bogotá - Colombia. Congreso, f. 7. http://www.bdigital.unal.edu.co/25925/1/23426-81530-1-PB.PDF

"Por el cual se crea el Instituto Colombiano de Especialización Técnica en el Exterior". Portal del Ministerio de Educación Nacional (PMEN), Bogotá - Colombia. Presidente, f.6. https:// www.mineducacion.gov.co/1621/articles-103405_archivo_pdf.pdf

"Por el cual se dictan disposiciones relacionadas con las Facultades Universitarias Oficiales y Privadas". Portal del Ministerio de Educación Nacional (PMEN), Bogotá - Colombia. Presidente, f.1. http://www.suin-juriscol.gov.co/viewDocument.asp?ruta=Decretos/1058816

"Por el cual se provee el desarrollo de las Universidades colombianas. Portal del Ministerio de Educación Nacional (PMEN), Bogotá - Colombia. Presidente, f.3. https://www.funcionpu-

59 Mario Díaz Villa, "Currículum: debates actuales. Trazos desde América Latina", Pedagogía y Saberes n. 40 (2014): 7. https://doi. org/10.17227/01212494.40pys35.45 (7 de abril, 2020).

60 Luis Alberto Malagón Plata, "El currículo: dispositivo pedagógico para la vinculación universidad-sociedad”, Revista electrónica de la Red de Investigación Educativa vol. 1, n. ${ }^{\circ} 1$ (2004). http://revista.iered.org/v1n1/pdf/lmalagon.pdf (7 de abril, 2020). 
blica.gov.co/eva/gestornormativo/norma.php?i=67181

"Por la cual se organiza la educación técnica". Portal del Ministerio de Educación Nacional (PMEN), Bogotá - Colombia. Congreso, f.4. https://www.mineducacion.gov.co/1759/articles-103456_archivo_pdf.pdf

"Sobre ejercicio de la profesión de ingeniería agronómica". Portal del Ministerio de Educación Nacional (PMEN), Bogotá - Colombia. Presidente, f. 4. https://www.mineducacion.gov. co/1621/articles-103446_archivo_pdf.pdf

"Sobre el plan de estudios". Secretaría Jurídica Distrital (SJD), Bogotá - Colombia. Poder Ejecutivo. http://www.alcaldiabogota.gov.co/sisjur/normas/Norma1.jsp?i=13658

"Sobre instrucción pública". Secretaría Jurídica Distrital (SJD), Bogotá - Colombia. Congreso, f. 3. http://www.alcaldiabogota.gov.co/sisjur/normas/Norma1.jsp?i=12626

Oficina de Archivo de la Universidad del Tolima (OAUT). Ibagué - Colombia. Jefe civil y militar del Departamento, f. 1.

Oficina de Archivo de la Universidad del Tolima (OAUT). Ibagué - Colombia. Gobernador del Departamento, f. 1.

Oficina de Archivo de la Universidad del Tolima (OAUT). Ibagué - Colombia. Consejo Superior, fs. 1,31 .

Oficina de Archivo de la Universidad del Tolima (OAUT). Ibagué - Colombia. Consejo Directivo, f. 3. Oficina de Archivo de la Universidad del Tolima (OAUT). Ibagué - Colombia. Asamblea, f. 1.

\section{REFERENCIAS}

Ahern, Evelyn. “El desarrollo de la educación en Colombia: 1820-1850”. Revista Colombiana de Educación n. $22-23$ (1991).

Alfonso López, 1886-1959". En Antología del pensamiento político colombiano. Tomo II: Siglo XX, selección, introducción y notas de Jaime Jaramillo Uribe. Bogotá: Banco de la República - Biblioteca Luis Ángel-Arango, 1970. http://babel.banrepcultural.org/cdm/ref/collection/p17054coll18/id/455 (25 de mayo, 2017).

Anuario de la Universidad de Palmira (1954). file:///C:/Users/USUARIO/Downloads/PLAN\%20DE\%20 ESTUDIOS\%20AGRONOMIA\%201954.pdf

Ararat, Catalina. “¿Por quién votará usted?: campaña política para la presidencia de la República de Colombia, 1946". CS n. 12 (2013). http://www.scielo.org.co/pdf/recs/n12/n12a17.pdf (12 de abril, 2017).

Arias de Greiff, Jorge y Clara Helena Sánchez. "Antecedentes de la Facultad de Ciencias". En Facultad de Ciencias: fundación y consolidación de comunidades científicas, editado por Germán Cubillos Alfonso. Bogotá: Unibiblos Universidad Nacional de Colombia, 2006.

Asamblea del Tolima. “Ordenanza 05 de 1945 (mayo 10)". Revista Avance y Desarrollo n. ${ }^{\circ}$ (1989): 5.

Baicué Peña, José Eliseo. “Educación superior en un espacio de frontera: historia y desarrollo académico de la universidad Surcolombiana, 1970-2010". Tesis de maestría en Historia, Universidad Nacional de Colombia, 2009. 24. 25

Betancourt Serna, Fernando, "Universidad Ilustrada Neogranadina e Independencia de Colombia (1810 - 2010)". Revista Historia de la Educación Latinoamericana n. ${ }^{\circ} 14$ (2010). http://www.scielo.org.co/ scielo.php?script=sci_arttext\&pid=S0122-72382010000100004\&lng=en\&tlng=es. (12 de junio, 2017).

Biblioteca Nacional de Chile, "El chileno que vino de Venezuela. Andrés Bello López (1781-1865)". http://www.memoriachilena.cl/602/w3-article-3290.html (8 de julio, 2017).

Borrero Cabal, Alfonso. La universidad. Estudios sobre sus orígenes, dinámicas y tendencias. Bogotá: Editorial Pontificia Universidad Javeriana, 2008.

Brunner, José Joaquín. Educación Superior en América Latina: cambios y desafios. Chile: Fondo de Cultura Económica, 1990.

Carvajal Herrera, Carlos Roberto y José del Carmen Buitrago. “Constitución y primeros años de funcionamiento de la Universidad del Tolima 1945-1958". Revista Aquelarre 2, n. ${ }^{\circ}$ (2003): 41-51.

Cuéllar Velandia, César Augusto. “Decreto 1916 de 1954 (octubre 25)”. Revista Avance y Desarrollo n. ${ }^{\circ}$ (1989): 5. 
Cuéllar Velandia, César Augusto. “Decreto 357 de 1955 (marzo 10)”. En Reportaje a la Universidad. Ibagué: Universidad del Tolima/Vicerrectoría de Desarrollo Humano, 1996.

Díaz Soler, Carlos Jilmar. "Formación e investigación: Una discusión a propósito del Instituto Jean-Jacques Rousseau, de Ginebra, Suiza (1912-1947)". Pedagogía y Saberes n. ${ }^{\circ}$ 43. (2015): 133-147. https:// revistas.pedagogica.edu.co/index.php/PYS/article/view/3876 (20 de mayo, 2018).

Díaz Soler, Carlos Jilmar. “Las revistas impresas ‘Educación’ y la (re)orientación de las prácticas pedagógicas. Historias vinculadas entre São Paulo y Bogotá, 1932-1939". Revista Historia de la Educación Latinoamericana 15, n. 20 (2013). http://www.redalyc.org/articulo.oa?id=86929738006 (9 de julio, 2017).

Díaz Villa, Mario. "Currículum: debates actuales. Trazos desde América Latina”. Pedagogía y Saberes n. 40, 2014. https://doi.org/10.17227/01212494.40pys35.45 (7 de abril, 2020)

Giraldo Pérez, Sonia. “La Universidad del Tolima: los años de su institucionalización (1945-1962). Hacia una discusión sobre la universidad y el currículo". Tesis de maestría en Educación, Universidad Santo Tomás, 2016. 73. 76.

Gómez Delgado, Julián Alberto. “El trabajo de la Misión de Economía y Humanismo en Colombia 1954-1958". Tesis de pregrado en Sociología, Pontificia Universidad Javeriana, 2015. https:// repository.javeriana.edu.co/handle/10554/15937 (24 de abril, 2017)

Gómez Marín, Omar, Sergio Gómez Restrepo e Idilio Urrego Giraldo. “La educación en Colombia en el siglo XX. 1900 - 1980". Tesis de maestría en Educación, Universidad de Antioquia, 1982, 264. 267. 269. 270.

Ibarra Losada, María Clara. "Fundación de la universidad pública del Huila: Años del Itusco". Tesis de maestría en Historia, Universidad Nacional de Colombia, 2011, 29. 30. http://www.bdigital. unal.edu.co/4020/1/468382.2011_pte_1.pdf (05 de marzo, 2015)

Jaramillo Marín, Jefferson. Pasados y presentes de la violencia en Colombia. Estudios sobre las comisiones de investigación (1958/2011). Bogotá: Editorial Pontificia Universidad Javeriana, 2014.

“Jorge Eliécer Gaitán, 1898-1948”. En Antología del pensamiento político colombiano. Tomo II: Siglo XX, selección, introducción y notas de Jaime Jaramillo Uribe. Bogotá: Banco de la República - Biblioteca Luis Ángel-Arango, 1970. http://babel.banrepcultural.org/cdm/ref/collection/p17054coll18/ id/455 (25 de mayo; 13 de abril, 2017).

Luna Eslava, Leonardo. “La circulación de conocimientos y la discusión sobre la infancia: análisis desde la Revista Educación, 1933-1935". Revista Iberoamericana de Psicología: Ciencia y Tecnología 9, n. 1 (2016): 33-44.

Malagón Plata, Luis Alberto. "El currículo: dispositivo pedagógico para la vinculación universidad-sociedad". Revista electrónica de la Red de Investigación Educativa 1, n. ${ }^{\circ}$ 1, 2004. http://revista.iered. org/v1n1/pdf/lmalagon.pdf (7 de abril, 2020).

"Mariano Ospina Rodríguez, 1805-1885". En Antología del pensamiento político colombiano. Tomo I: Siglo XIX, selección, introducción y notas de Jaime Jaramillo Uribe. Bogotá: Banco de la República - Biblioteca Luis Ángel-Arango, 1970. http://babel.banrepcultural.org/cdm/ref/collection/ p17054coll18/id/455 (14 de noviembre, 2016).

Mendoza Morales, Alberto. Evolución histórica de las divisiones político administrativas de Colombia desde 1509 hasta hoy (Bogotá: Boletín Sociedad Geográfica de Colombia, 1989). http://www.sogeocol. edu.co/documentos/evol_fron.pdf (15 de noviembre, 2016).

Molina Rodríguez, Carlos Alberto. “1958, La Asociación Colombiana de Universidades: un interés gremial". En FUN-ASCUN en la historia del sistema universitario colombiano, 1958-1968, editado por Carlos Alberto Molina Rodríguez. Bucaramanga: UIS, 2013.

Montoya, Rafael Iván. “Reseña histórica de la Facultad de Medicina Veterinaria y Zootecnia”. Revista Avance y Desarrollo n. ${ }^{\circ} 1$ (1989).

Mosquera, José María. “Apuntes para una historia de la Facultad de Ingeniería Agronómica de la Universidad del Tolima". Revista Avance y Desarrollo n. ${ }^{\circ} 1$ (1989).

Navascues, Pedro. Sobre las artes mecánicas. España: Ars mechanicae [catálogo de exposición Ingeniería medieval en España]. http://oa.upm.es/10507/1/arsmechanicae.pdf (8 de febrero, 2017).

Ocampo López, Javier. "Historiografía de la Universidad Republicana". En Historia de la Universidad Colombiana, editado por Diana Soto Arango. Tunja: Universidad Pedagógica y Tecnológica de Colombia, 1998.

Ocampo López, Javier. "Manuel María de los Santos Acosta". En Gran Enciclopedia de Colombia (Bogotá: Biblioteca virtual Luis Ángel Arango). http://www.banrepcultural.org/blaavirtual/biografias/ acossant.htm (07 de junio, 2017). 
Organización de Estados Iberoamericanos para la Educación, la Ciencia y la Cultura/MEN/ICETEX, "Sistemas Educativos Nacionales - Colombia", 1993. https://www.google.es/url?sa=t\&rct=j\&$\mathrm{q}=\&$ esrc $=$ s\&source=web\&cd=1\&ved=2ahUKEwiZ2JLE79noAhWknuAKHStPAn0QFjAAegQIAhAB\&url=https\%3A\%2F\%2Fwww.oei.es\%2Fhistorico\%2Fquipu\%2Fcolombia\%2Fcol02. pdf\&usg=AOvVaw32nW0B8Qed3aR-IRuXIh4q (14 de febrero, 2017).

Ortiz, Blanca Inés. "Aproximación a la historiografía y fuentes de la Universidad Distrital Francisco José de Caldas". En Historia de la universidad colombiana, editado por Diana Soto Arango. Tunja: Universidad Pedagógica y Tecnológica de Colombia, 1998.

Parra Escobar, Néstor Hernando. “La Universidad del Tolima y la reestructuración de la educación superior en Colombia". En Obras selectas de N. H. Parra. Tomo 3: Educación y desarrollo humano. Ibagué: Universidad de Ibagué, 2013.

Pérez Salamanca, Camilo. "Yo derroqué al gobernador Gilberto Polanco". En Reportaje a la Universidad. Ibagué: Universidad del Tolima/Vicerrectoría de Desarrollo Humano, 1996.

Salazar, Boris. "Currie y Colombia: El asesor que vino de lejos". Estudios Gerenciales 19, n. ${ }^{\circ} 86$ (2003) http://www.scielo.org.co/scielo.php?script=sci_arttext\&pid=S0123-59232003000100004 (20 de abril, 2017).

Sánchez, Ángel. “Gaitanismo y nueve de abril”. Papeles políticos 13, n. ${ }^{\circ} 1$ (2008): 13-49. http://www.scielo. org.co/pdf/papel/v13n1/v13n1a02.pdf_(28 de febrero, 2017).

Sánchez, Gonzalo. Los días de la revolución: gaitanismo y 9 de abril en provincia. Bogotá: Centro Cultural Jorge Eliécer Gaitán, 1984.

Soto Arango, Diana. "Aproximación histórica de la universidad colombiana". Revista Historia de la Educación Latinoamericana 7 (2005): 101-138.

Soto Arango, Diana. Historia de la universidad colombiana. Tomo I: Historiografía y Fuentes. Tunja: Universidad Pedagógica y Tecnológica de Colombia, 1998.

Valencia Llano, Alfonso. "El general José Hilario López, un liberal civilista”. Revista Credencial Historia n. ${ }^{\circ}$ 98, 1998 (Bogotá: Biblioteca virtual Luis Ángel Arango) https://www.banrepcultural.org/ biblioteca-virtual/credencial-historia/numero-98/el-general-jose-hilario-lopez-un-liberal-civilista (07 de junio, 2017).

Vásquez, Claudia. “Tomás Cipriano de Mosquera”. En Gran Enciclopedia de Colombia (Bogotá: Biblioteca virtual Luis Ángel-Arango). http://www.banrepcultural.org/blaavirtual/biografias/mosqtoma. htm (14 de noviembre, 2016).

Cómo citar:

Giraldo Pérez, Sonia. Universidad y currículo: El caso de la Universidad del Tolima (1955 A 1962)". Revista Historia de la Educación

Latinoamericana. vol. 22 No. 34 (2020): 243-264

DOI: https://doi.org/10.19053/01227238.10904

(c) (i) @) Esta obra está bajo una licencia Creative Commons. Reconocimiento-No Comercial-Sin Obra Derivada 2.5 Colombia. 